The BMJ

Cite this as: $B M / 2021 ; 374: \mathrm{n} 1812$ http://dx.doi.org/10.1136/bmj.n1812 Published: 03 August 2021

\title{
How can I keep in touch with colleagues?
}

\section{Frequently changing roles and workplaces can make it hard to stay in touch with colleagues. Abi Rimmer hears some tips on how to stay connected}

Abi Rimmer

\section{Virtual communication is essential}

Sabrina Das, obstetrician and gynaecologist with Médecins Sans Frontières (MSF) in Yemen, says, "I'm on sabbatical working in Yemen with MSF. Keeping in touch with colleagues from the UK has been vitally important to me as an informal support system. I am the only international MSF obstetrician and gynaecologist working on this project, and my ability to move around the area is severely curtailed. My accommodation is located within the hospital and, for security reasons, I rarely leave the building.

"WhatsApp messaging and video calls have formed the mainstay of my communication with colleagues. I set up a closed WhatsApp group to post near-daily updates to reassure my friends, family, and colleagues that I am safe and this has helped me have regular connection with the people who care about me.

"I also have a small and trusted group of "phone a friend' specialist colleagues. With the virtual guidance of these experts I've been able to perform procedures that I had minimal experience of in $\mathrm{my}$ usual UK practice. These colleagues also help me to process the maternal and fetal deaths emotionally, and a multitude of other 'not rare for Yemen' presentations.

"Coming from an international family who live across four different time zones, I'm used to using group chats to talk about things that are often very personal. During my sabbatical, I've maintained an emotional connection with friends and colleagues through these virtual methods-following a colleague through her second and third trimesters of pregnancy, giving another advice about exams, giving a virtual hug to my trainee who was stressed about their annual review of competency progression, and high fiving another who got her audit published.

"My highlight of staying in touch with colleagues has to be attending the weekly Teams improvement meeting one week - the team made me the guest star. I loved seeing the smiling faces of my maternity colleagues. I was so proud they were keeping the meeting going even in my absence.

"During my darkest moments of self-doubt and imposter syndrome, my colleagues have been able to remind me that I am loved and missed back home, and that I am a skilled and experienced obstetrician. In a war torn country, it's impossible to save every mother and every child, but I'm doing my best and wouldn't be here without all the virtual support I have received from home."

\section{Have informal check ins with colleagues}

Claire Pulford, member of National Association of Clinical Tutors (NACT) UK Council, director of medical education, and consultant physician, says, "Keeping in touch with colleagues is good for us-humans are social animals. It offers us a sense of belonging and we can access support, advice, feedback, ideas, and guidance.

"But it's not just good for individuals-it also has benefits for professional practice where learning is not just about what we know but also how we do it. Within an organisation, good communication can strengthen teams, increase trust, and boost productivity.

"Take some time to reflect on who your colleagues might be and think more widely than your immediate team. Include a range of grades and professional groups. If you have a need or interest why not look for an existing group and, if you can't find one, invite others to start one with you.

"A professional lifesaver for me has been the ability to connect to other educators, especially the NACT Council group which has provided a stream of interesting ideas, good humour, mutual support, and the power of the 'hive mind.'

"Try to create some informal space at work to check in with how your colleagues are-it only takes a minute. I want to thank those who have checked in with me-sometimes it's been the one thing that turned a difficult day into a manageable one.

"Some of the relationships you have with colleagues will last for years-they'll know what you're like at your worst as well as your best, during sleepless nights, and maybe before you had expert knowledge or experience. They've commiserated and celebrated with you. They may well have known you longer than your partner and will know what pressures doctors face. Long term friendships like this can give you grounding and perspective, and-with luck-will outlast your career.

"Creating and keeping in touch with a network of colleagues is not an optional extra, it's good personal, professional, and organisational practice. Be proactive, be interested in others, be kind. Offer support to others, be willing to accept it when it is offered to you, and don't be afraid to ask for help if you need it."

\section{Find time for face-to-face catch ups}

Nusra Khodabux, specialty trainee year 4 in psychiatry of intellectual disability, Leicestershire Partnership NHS Trust, says, “As doctors, we spend 
a large part of our post-university life rotating through different regions and occasionally even different countries. In doing so, our social network undoubtedly expands. Keeping in touch with past colleagues can be challenging but I've also found it rewarding.

“From a personal point of view, it's always been about the quality of the relationships I've built with a select number of colleagues as opposed to the quantity.

"Social media have made interactions across geographical boundaries much simpler. I have a few WhatsApp groups with past colleagues where I'm active, and also use likes or comments on Facebook to keep in touch with others while simultaneously maintaining a healthy distance, and not being overly friendly.

"A handful of colleagues have become close friends over time. To maintain these relationships, I've found it important to find time for face-to-face catch ups. These may be over coffee or dinner when in each other's vicinity. With close colleagues who have children of the same age as mine, we may plan whole family get togethers once or twice a year.

"Social distancing rules have, of course, thrown a spanner in the works. For the past 18 months, I haven't physically seen some colleagues I used to meet every month during journal clubs or deanery teaching.

"Virtual platforms (such as Teams or Zoom) have allowed some interaction during those organised sessions but they're not optimally designed for regular informal chats between colleagues, which can sometimes be more valuable than the teaching itself. I know some friends who have started doing 'virtual coffees' where colleagues dedicate specific times to catch up.”

\section{Bake, WhatsApp, walk, phone, and email}

Cindy Chew, consultant radiologist and honorary clinical associate professor, University of Glasgow, says, "When people think of radiologists, grumpy folk, hidden in the darkest, most inaccessible crevices of hospitals, hunched over computer screens may come to mind. That is if they even know what radiologists are.

"In fact, radiologists are sociable people, ever keen to discuss interesting cases with other clinicians. With social distancing and ever increasing imaging demands, collegiate contact has become quite challenging. So how do I keep in touch with colleagues-radiological and clinical?

"Radiologists communicate daily with colleagues through reports. The ubiquitous telephone and emails are still there, as are the failsafe alerts for unexpected or urgent findings on imaging examinations.

"I bake for my department. I Whatsapp the latest Twitter offering of teaching webinars or conference abstract calls to our registrars. I pester my recently relocated colleague for walks to touch base on how they are getting on with the new job and family lives.

"I also order Fortnum and Mason hampers for others who are celebrating wedding anniversaries. Hopefully I can gather folk around a round table to share a hearty meal again soon.” 